\title{
Provision of hormonal and long-acting reversible contraceptive services by general practices in Scotland, UK (2004-2009)
}

\author{
Anusha Reddy, ${ }^{1}$ Margaret Watson, ${ }^{2}$ Philip Hannaford, ${ }^{3}$ Karen Lefevre, ${ }^{4}$ \\ Dolapo Ayansina ${ }^{5}$
}

\begin{abstract}
${ }^{1}$ Medical Student, University of Aberdeen, Aberdeen, UK

${ }^{2}$ Senior Research Fellow, Centre of Primary Academic Care, University of Aberdeen, Aberdeen, UK

${ }^{3}$ NHS Grampian Professor of Primary Care, Centre of Primary Academic Care, University of Aberdeen, Aberdeen, UK

${ }^{4}$ General Practitioner Principal, Centre of Primary Academic Care, University of Aberdeen, Aberdeen, UK

${ }^{5}$ Research Fellow, Centre of Primary Academic Care, University of Aberdeen, Aberdeen, UK
\end{abstract}

\section{Correspondence to} Ms Anusha Reddy, Centre of Academic Primary Care, University of Aberdeen, Polwarth Building, Foresterhill, Aberdeen AB25 2ZD, UK; a.reddy.08@aberdeen.ac.uk

Received 3 September 2012 Revised 16 January 2013 Accepted 25 February 2013 Published Online First 21 May 2013
To cite: Reddy A, Watson $M$, Hannaford $\mathrm{P}$, et al. J Fam Plann Reprod Health Care 2014;40:23-29.

\begin{abstract}
Background In the UK, a large proportion of contraceptive services are provided from general practice. However, little is known about which contraceptive services are provided and to whom.

Study design Descriptive serial cross-sectional study of women aged 12-55 years, registered with 191 general practices in Scotland, UK between 2004 and 2009.

Results Annual incidence of provision of hormonal and long-acting reversible contraceptives (LARCs) increased from $27.7 \%$ in 2004 to $30.1 \%$ in 2009 . Amongst those women registered with a general practice for the full 5 -year period the provision of LARCs increased from $8.8 \%$ to $12.5 \%(p<0.001)$. For the same group, the provision of emergency hormonal contraception (EHC) decreased from $5.2 \%$ to $2.6 \%(p<0.001)$.

Conclusions With the exception of EHC, there was an increase over time in the provision of hormonal contraceptives and LARCs from general practices. It is important that a full range of contraceptive options remains easily available to women.
\end{abstract}

\section{INTRODUCTION}

The UK has a high rate of unintended pregnancies, despite its high use of contraception. ${ }^{1}{ }^{2}$ To tackle this issue, the National Health Service has developed and implemented various policies, including The Sexual Health Care Strategy in England ${ }^{3}$ and The Respect and Responsibility Sexual Health Strategy in Scotland. ${ }^{4}$ The most recent change has been to provide levonorgestrel-containing emergency hormonal contraception (EHC) free of charge, without requiring a prescription and
Key message points

- General practice provides a large proportion of contraceptive services; little is known about which services are provided and to whom.

- With the exception of emergency hormonal contraception, provision of hormonal contraceptives and long-acting reversible contraceptives from general practices has increased over recent years.

- It is important that a full range of contraceptive options remains readily available to women.

available over-the-counter from community pharmacies. This provision was introduced first in Scotland in 2008, and was followed by its introduction in Wales and selected pilot sites in England from April 2011 onwards. ${ }^{5}$ Before 2008, EHC was available without prescription but at a cost of approximately $£ 22.00(28 €),{ }^{7}$ which may have been a deterrent to its use.

Currently, general practices, community reproductive health clinics and community pharmacies are the main sources of contraception in the UK. In addition to ensuring good access to contraception, it is important that a wide range of contraceptive methods is available. Reversible methods that rely least on user compliance are termed long-acting reversible contraceptives (LARCs) and comprise intrauterine devices/systems (IUD/IUS), hormonal implants, and injectables. Despite their theoretical advantages, uptake and awareness of LARCs remains 
low. $^{28}$ With this in mind, in 2005 the UK's National Institute for Health and Clinical Excellence (NICE) introduced guidelines that promoted greater use of LARCs. ${ }^{8}$

These strategies have aimed to optimise reproductive health and decrease unintended pregnancies. However, little is currently known about the provision of contraceptive services from general practice. This study explored whether patterns of contraceptive provision from general practice have changed in recent years. It examined the provision of hormonal contraception and LARCs to women aged $12-55$ years by general practices in Scotland over the 5-year period 2004-2009.

\section{METHODS}

Most general practices in the UK now hold patient medical records on computer systems, including information about medicines prescribed. The Primary Care Clinical Informatics Unit (PCCIUR) of the University of Aberdeen (http://www.abdn.ac.uk/pcciu/PCCIUR. $\mathrm{htm}$ ) has collected computerised data from a variable number of volunteer general practices throughout Scotland biannually. Anonymous extracted data for each registered patient includes demographic data, clinical events coded using Read codes and prescription data. This study used information from the Spring 2009 dataset, which covered the years from 1 April to 31 March 2005 to 2009 and which contained data from 191 general practices.

\section{Annual incidence of contraceptive service provision}

From the dataset, cross-sectional (study year) samples were created of all women aged 12 to 55 years inclusive who were registered with the practices during each of the study years. These samples enabled the incidence of contraceptive service provision to be calculated.

For each study year, we determined whether the general practice records for each identified woman contained a record during the year of one or more prescriptions for: combined oral contraceptive (COC), progestogen-only pill (POP), contraceptive patch or ring, EHC or LARC [intrauterine copper device (IUD), progestogen-containing intrauterine system (IUS), progestogen-only implant or injection]. For example, for women registered at 1 April 2004, prescribing data were searched for relevant prescriptions issued during the period 1 April 2004 to 31 March 2005. The socioeconomic status for each woman (based on her postcode, using the Carstairs index ${ }^{9}$ ) and smoking status (past/current/never/unknown) were also ascertained.

\section{Contraceptive service provision among women registered for the entire 5-year period}

An additional dataset was constructed that included all women who were consistently registered with their general practice throughout the 5 -year observation period (i.e. 1 April 2004 to 31 March 2009). This was done to assess whether changes seen in the larger cross-sectional samples were an artefact introduced by studying multiple samples that could contain a different set of women each time. The same data as described above were ascertained for women registered for the entire period.

\section{Statistical analysis}

Using SPSS V.18.0 (IBM Corporation, New York, NY, USA), the 1-year incidence of provision of different contraceptives was determined for all women, as well as in age-specific groups (i.e. 12-15, 16-19, 20-35, $36-45$ and $46-55$ years). Only the first recording of each method during each study year was used when calculating the annual incidence of contraceptive provision. Logistic regression was used on the latest sample (2008-2009) to assess the likelihood of contraceptive provision by age, deprivation and smoking status.

For women registered for the entire period, three separate analyses were carried out using McNemar's Test to compare:

- The proportion of women who were provided with any contraceptive service between the first (2004-2005) and last study year (2008-2009).

- The change in LARC provision following the introduction of the NICE guidelines for increased provision of LARCs in 2005 (2004-2005 was compared with 2005-2009). ${ }^{8}$

- The impact of free provision of EHC from community pharmacies in Scotland after 2008 (2008-2009 was compared with 2004-2008). ${ }^{5}$

\section{RESULTS}

\section{Annual incidence of contraceptive service provision}

Each study year contained information from approximately 340000 women of reproductive age (Table 1). Between 2004-2005 and 2008-2009, the proportion of women provided with any reversible method of contraception increased from $27.7 \%$ [95\% confidence interval (CI) $27.5-27.8]$ to $30.1 \%$ (95\% CI 30.0-30.3). The most frequently provided contraceptive was the COC, increasing from $17.7 \%$ (95\% CI $17.5-17.8)$ in 2004-2005 to $18.3 \%$ (95\% CI 18.2-18.4) in 20082009. Also of note, the provision of POP increased by almost two-thirds from $2.8 \%$ (95\% CI 2.8-2.9) in 2004-2005 to $4.6 \%$ (95\% CI 4.5-4.7) in 2008-2009. Over time, the provision of any LARC method increased slightly from $7.6 \%$ (95\% CI 7.5-7.7) to $8.1 \%$ (95\% CI 8.0-8.2). Among the LARCs, the IUDs were the most commonly provided method, although their use decreased from 5.1\% (95\% CI 5.0-5.2) in 2004-2005 to $4.7 \%$ (95\% CI 4.6-4.7) of overall contraceptive provision in 2008-2009. The ratio of IUD:IUS was 4:1 in 2004-2005 and 1.8:1 in 2008-2009. The other two LARC methods examined - implants and injectables showed contrasting trends over the 5 -year period. The provision of implants increased from $0.1 \%$ (95\% CI $0.1-0.1)$ to $0.4 \%(95 \%$ CI $0.4-0.5)$, while injectables 
Table 1 Annual incidence of provision of contraceptive services by general practices $(n=191)$ in Scotland, UK to women aged 12-55 years

\begin{tabular}{|c|c|c|c|c|c|c|c|c|c|}
\hline \multirow[b]{2}{*}{ Year (number of women) } & \multirow[b]{2}{*}{$\mathrm{COC}$} & \multirow[b]{2}{*}{ POP } & \multirow[b]{2}{*}{ EHC } & \multicolumn{4}{|l|}{ LARCs } & \multirow{2}{*}{$\begin{array}{l}\text { Any LARC } \\
\text { methods }\end{array}$} & \multirow{2}{*}{$\begin{array}{l}\text { Any of these } \\
\text { methods of } \\
\text { contraception }\end{array}$} \\
\hline & & & & IUD & IUS & Implant & Injectable & & \\
\hline $2004-2005(n=335$ 392) & $17.7(17.5-17.8)$ & $2.8(2.8-2.9)$ & $3.0(3.0-3.1)$ & $5.1(5.0-5.2)$ & $1.3(1.3-1.4)$ & $0.1(0.1-0.1)$ & $1.9(1.8-1.9)$ & $7.6(7.5-7.7)$ & $27.7(27.5-27.8)$ \\
\hline $2005-2006(n=336450)$ & $18.2(18.0-18.3)$ & $3.3(3.3-3.4)$ & $2.8(2.7-2.8)$ & $5.1(5.0-5.1)$ & $1.7(1.6-1.7)$ & $0.2(0.2-0.2)$ & $1.8(1.7-1.8)$ & $7.7(7.6-7.8)$ & $28.6(28.4-28.7)$ \\
\hline $2006-2007(n=338793)$ & $18.2(18.1-18.4)$ & $3.8(3.8-3.9)$ & $2.6(2.5-2.6)$ & $5.0(4.9-5.0)$ & $2.0(2.0-2.1)$ & $0.2(0.2-0.2)$ & $1.7(1.7-1.8)$ & $7.8(7.7-7.9)$ & $29.2(29.0-29.3)$ \\
\hline 2007-2008 (n=339 510) & $18.3(18.2-18.5)$ & $4.2(4.2-4.3)$ & $2.5(2.4-2.5)$ & $4.9(4.8-4.9)$ & $2.4(2.3-2.4)$ & $0.4(0.3-0.4)$ & $1.7(1.6-1.7)$ & $8.0(7.9-8.1)$ & $29.8(29.6-29.9)$ \\
\hline $2008-2009(n=341514)$ & $18.3(18.2-18.4)$ & $4.6(4.5-4.7)$ & $2.3(2.3-2.4)$ & $4.7(4.6-4.7)$ & $2.8(2.7-2.8)$ & $0.4(0.4-0.5)$ & $1.7(1.6-1.7)$ & $8.1(8.0-8.2)$ & $30.1(30.0-30.3)$ \\
\hline
\end{tabular}

All data are presented as percentages ( $95 \%$ confidence intervals, Cls). The final two columns are mutually exclusive.

COC, combined oral contraceptive; EHC, emergency hormonal contraception; IUD, intrauterine device; IUS, intrauterine system; LARCs, long-acting reversible contraceptives; POP, progestogen-only pill.

Table 2 Provision of contraception in 2008-2009 in Scotland, UK by age, smoking and deprivation

\begin{tabular}{|c|c|c|c|c|c|c|}
\hline \multirow{2}{*}{ Study year } & \multicolumn{2}{|l|}{ Any contraceptive } & \multicolumn{2}{|l|}{ LARC } & \multicolumn{2}{|l|}{ EHC } \\
\hline & OR & $\mathrm{OR}_{\mathrm{adj}}$ & OR & $\mathrm{OR}_{\mathrm{adj}}$ & OR & $\mathrm{OR}_{\mathrm{adj}}$ \\
\hline \multicolumn{7}{|l|}{ Age group (years) } \\
\hline 12-15 & $0.13(0.13-0.14)$ & $0.27(0.26-0.29)$ & $0.14(0.11-0.16)$ & $0.35(0.28-0.42)$ & $0.21(0.18-0.25)$ & $0.48(0.40-0.58)$ \\
\hline $16-19 \dagger$ & 1.0 & 1.0 & 1.0 & 1.0 & 1.0 & 1.0 \\
\hline $20-35$ & $1.27(1.23-1.30)$ & $1.07(1.04-1.10)$ & $1.98(1.86-2.11)$ & $1.72(1.61-1.83)$ & $1.03(0.97-1.11)$ & $0.90(0.84-0.96)$ \\
\hline $36-45$ & $0.62(0.61-0.64)$ & $0.51(0.50-0.53)$ & $3.01(2.82-3.21)$ & $2.58(2.42-2.74)$ & $0.42(0.39-0.46)$ & $0.36(0.33-0.39)$ \\
\hline $46-55$ & $0.24(0.24-0.25)$ & $0.20(0.19-0.20)$ & $1.94(1.81-2.07)$ & $1.64(1.54-1.75)$ & $0.10(0.09-0.12)$ & $0.09(0.08-0.10)$ \\
\hline \multicolumn{7}{|l|}{ Smoking status } \\
\hline Never smoked $†$ & 1.0 & 1.0 & 1.0 & 1.0 & 1.0 & 1.0 \\
\hline Current smoker & $1.00(0.98-1.02)^{\star *}$ & $1.02(1.00-1.04)^{\star *}$ & $1.56(1.52-1.61)$ & $1.49(1.44-1.53)$ & $1.81(1.72-1.90)$ & $1.91(1.81-2.00)$ \\
\hline Ex-smoker & $0.99(0.97-1.01)^{* *}$ & $1.12(1.10-1.14)$ & $1.43(1.38-1.48)$ & $1.34(1.29-1.39)$ & $1.19(1.11-1.28)$ & $1.41(1.32-1.52)$ \\
\hline \multicolumn{7}{|l|}{ Deprivation category } \\
\hline DepCat 1-3† (most affluent) & 1.0 & 1.0 & 1.0 & 1.0 & 1.0 & 1.0 \\
\hline DepCat 4 & $1.14(1.12-1.16)$ & $1.11(1.09-1.13)$ & $1.24(1.20-1.28)$ & $1.20(1.17-1.24)$ & $1.26(1.20-1.33)$ & $1.16(1.09-1.22)$ \\
\hline DepCat 5-7 (least affluent) & $1.06(1.04-1.08)$ & $0.99(0.97-1.01)^{\star *}$ & $1.11(1.07-1.14)$ & $1.05(1.02-1.08)^{\star}$ & $1.10(1.04-1.16)$ & $0.94(0.89-1.00)^{* *}$ \\
\hline
\end{tabular}

All data are presented as odds ratios with $95 \%$ confidence intervals. All values shown in table with $p<0.001$, except ${ }^{*} p<0.01$, and ${ }^{*}{ }^{*} p>0.05$.

tReference groups: age groups=16-19 years old; smoking status=never smoked; DepCat=Deprivation Category 1-3 (i.e. most affluent). 'Any contraceptive' includes combined oral contraceptive pill, or progestogen-only pill, or LARC or EHC.

EHC, emergency hormonal contraception; LARC, long-acting reversible contraceptive; OR, odds ratio; OR adj, adjusted OR (age, smoking and deprivation). 
1.1: Any methods of contraception combined

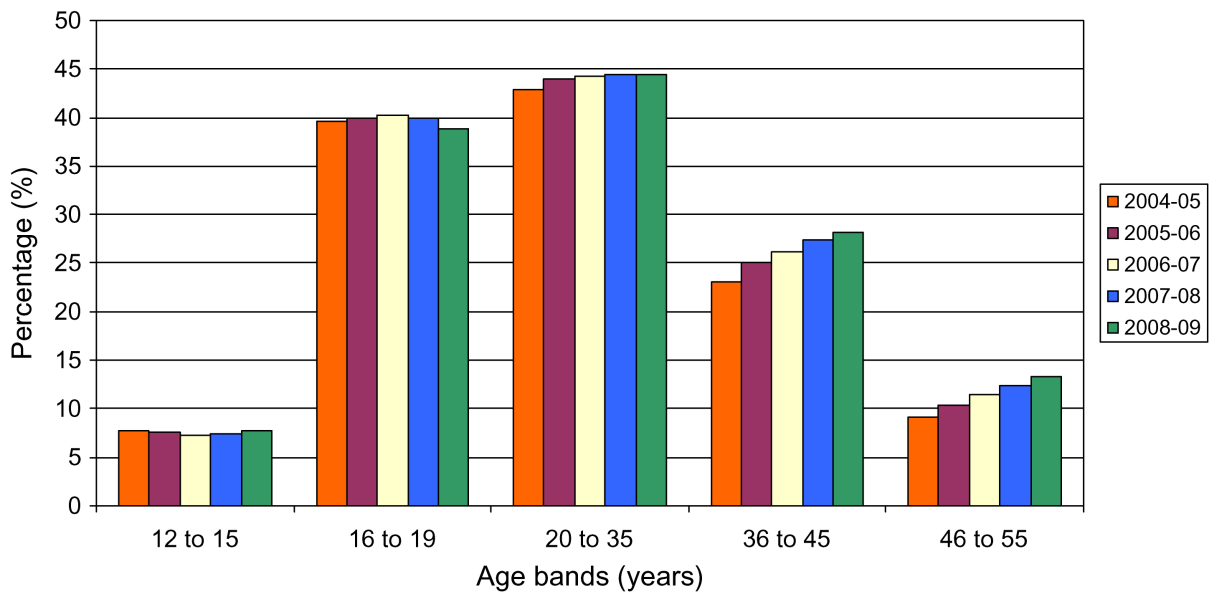

\section{2: Combined oral contraceptive}

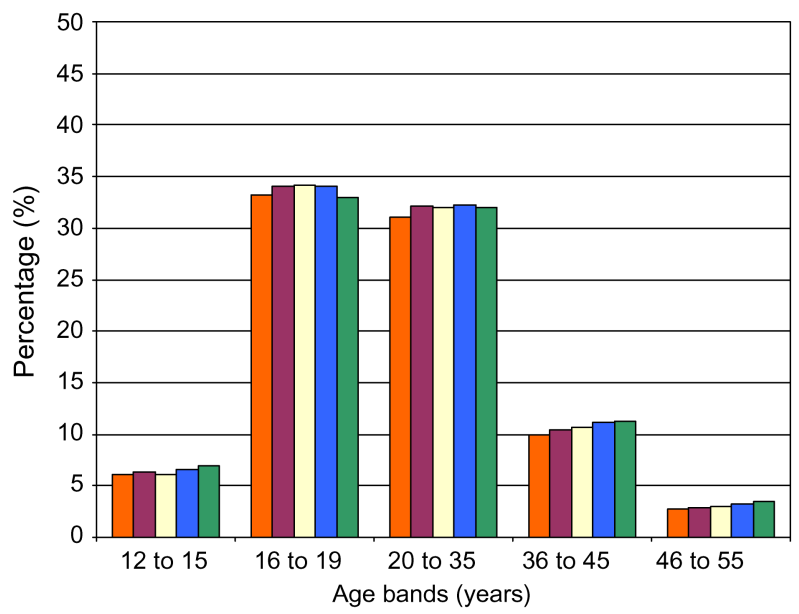

1.4: Long-acting reversible contraceptives

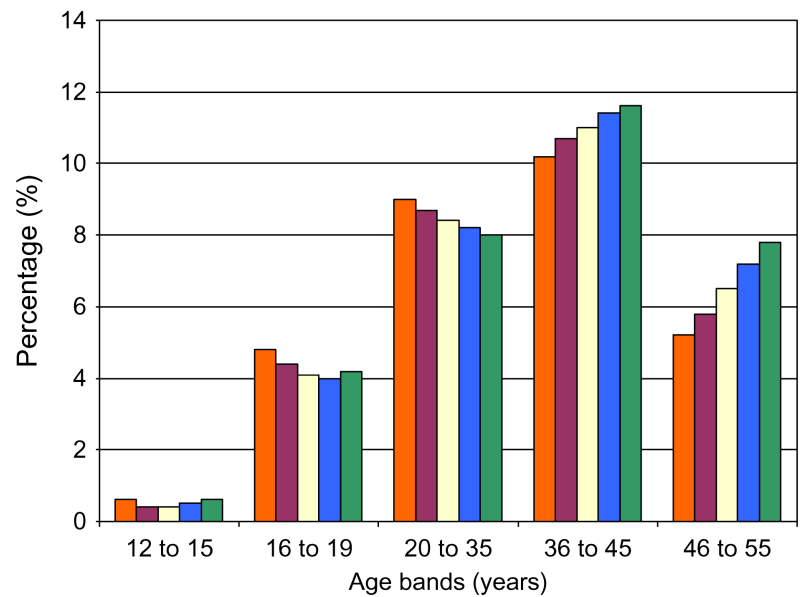

1.3: Progestogen-only pill

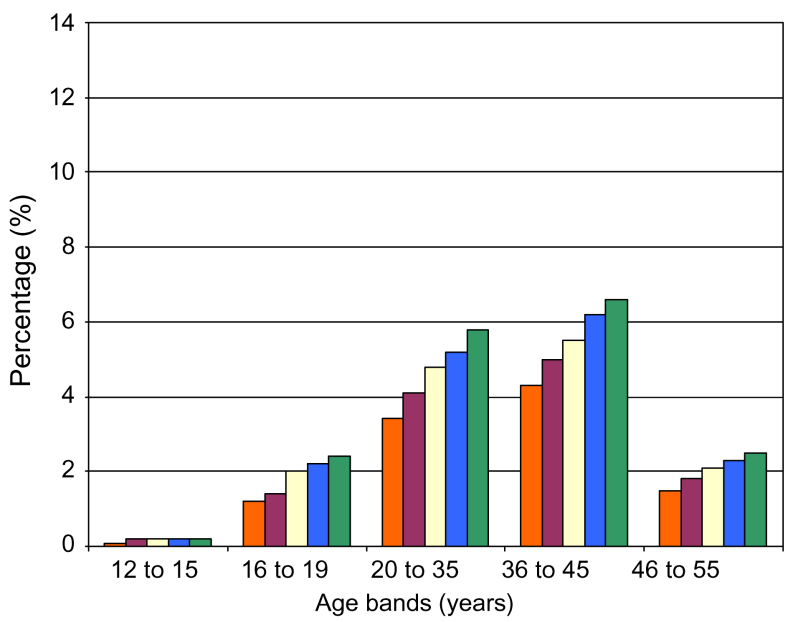

1.5: Emergency hormonal contraception

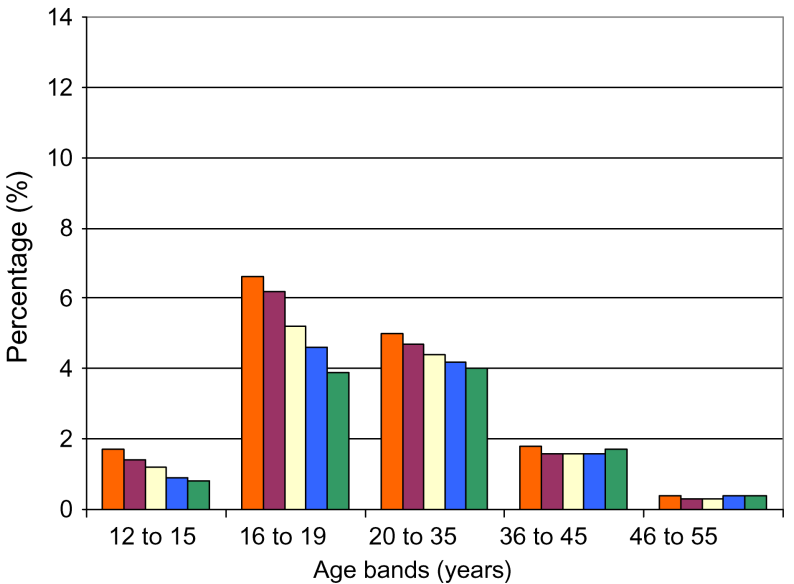

Figure 1 Percentage of women in different age groups provided with contraception during each study year. 1.1: Any methods of contraception combined. 1.2: Combined oral contraceptive. 1.3: Progestogen-only pill. 1.4: Long-acting reversible contraceptives. 1.5: Emergency hormonal contraception.

decreased from $1.9 \%(95 \%$ CI $1.8-1.9)$ to $1.7 \%(95 \%$ CI 1.6-1.7). General practice provision of EHC decreased from $3.0 \%$ (95\% CI 3.0-3.1) in 2004-2005 to $2.3 \%$ (95\% CI 2.3-2.4) in 2008-2009. Figures for the combined hormonal ring and combined patch in each year were $0 \%$ and $<0.2 \%$, respectively. 
Age-specific provision of contraception

Women aged between 16 and 35 years were the most frequent recipients of contraceptive services from general practice (Figure 1.1). In each of the five study years, the provision of contraception increased among women aged 20-55 years. However, no increases were seen in the youngest age groups (12-19 years). The COC was provided most frequently to women aged between 16 and 35 years (Figure 1.2). An increase in this method was found over time within the following age groups: 12-15, $36-45$ and $46-55$ years. The provision of POP increased in all age groups over time, except for 12-15 year olds (Figure 1.3). The most frequent recipients of LARCs were women aged $36-45$ years (Figure 1.4). The use of these contraceptives increased over time among older women. Women aged 16-19 years tended to be the most frequent recipients of EHC from general practice (Figure 1.5). However, the provision of EHC from general practices tended to decrease across all age groups with time.

\section{Provision of contraception by age, smoking and deprivation}

Using the 2008-2009 study year sample, and with adjustment for smoking and deprivation status, women aged between 20 and 35 years were significantly more likely to be provided with any contraceptive method than 16-19-year-olds (Table 2). Ex-smokers were more likely to be provided with any contraceptive service than non-smokers.

In the same sample, older women (aged $\geq 20$ years) were more likely to receive a LARC than 1619-year-olds, with the greatest provision among those aged 36-45 years. In comparison with non-smokers, LARCs were provided more often to smokers and ex-smokers. Women in the most affluent category were least likely to have a LARC prescribed.

While EHC was prescribed most frequently to women aged 16-19 years, older women (aged 46-55 years) were least likely to receive this service. Women who smoked were almost twice more likely than non-smokers to receive EHC.

\section{Contraceptive service provision among women registered for the entire period}

In total, 237206 women were registered for the entire 5 -year observation period. The provision of hormonal contraception and LARC methods increased significantly over time from $29.6 \%$ (95\% CI 29.4-29.7) in 2004-2005 to 31.9\% (95\% CI 31.7-32.1) in 2008$2009(p<0.001)$. The provision of LARCs increased from $8.8 \%$ in $2004-2005$ to $12.5 \%$ in $2005-2009$ $(p<0.001)$. A significant decrease occurred in the provision of EHC from general practice from 5.2\% in 2004-2008 to 2.6\% in 2008-2009 ( $p<0.001)$.

\section{DISCUSSION}

\section{Provision of contraceptive services in general practice}

General practices are a major source of contraceptive services for women in the UK. At present, most of the information regarding contraceptive usage comes from a multi-purpose Omnibus Survey, conducted monthly by the Office for National Statistics. ${ }^{2}$ These surveys do not record information about the different health care sources that provide contraceptive services. Our study therefore provides important information about patterns of contraceptive provision over time from one of the key service providers.

In 2005, the Scottish Government introduced its first national sexual health and relationships strategy. ${ }^{4}$ With a funding reservoir of $£ 15$ million it aimed not only to improve provision of contraception but also to promote good sexual health and education. ${ }^{4}$ Our study showed that between 2004 and 2009 there was an increase in contraceptive service provision by general practices in Scotland. Over the 5-year period, the most frequently provided method was COC. This is consistent with findings from the Omnibus Survey. ${ }^{2}$ Our study also showed an increase in the provision of POP. A new type of POP containing desogestrel $75 \mu \mathrm{g}$ $\left(\right.$ Cerazette $\left.^{\circledR}\right)$, with certain advantages over existing preparations, became available in the UK in 2002, increasing the options available to women wishing to use this method of contraception. ${ }^{10}$

In 2008-2009, 8.1\% of women received some type of LARC. This apparently low figure may be due to several causes including funding, education or time allocation. A previous study highlighted that one of the most likely reasons for low LARC usage was lack of trained staff able to fit specific LARCs (IUD, IUS or implants). ${ }^{11}$ Some practices in our sample may not have had trained staff and may therefore have referred patients to community reproductive health clinics. If this was the case, the observed value of $8.1 \%$ will be an underestimate of the overall use of LARCs in Scotland by all women of reproductive age. The reduction in the IUD:IUS ratio from $4: 1$ in 20042005 to $1.8: 1$ in $2008-2009$ is of interest. The change was mainly due to increased IUS provision during this period. IUS devices are licensed for the treatment of idiopathic menorrhagia as well as for contraception, ${ }^{10}$ which may account for some of the increase. In terms of the provision of implant and injectable methods of contraception, data from national Scottish statistics reveal similar trends in their patterns of use whether provided by general practice or from central pharmacies. ${ }^{12}$ One of the reasons for the decrease in injectable methods from 2004 onwards may have be due to concerns about the possible effects of the depot medroxyprogesterone acetate-containing contraceptive on bone mineral density in women aged $<18$ and $>45$ years. $^{8}$

Our study found a significant decrease in the provision of EHC from general practice over time. Since the introduction of free provision of EHC in 2008 there has been an increase in sales from community pharmacies; from $<6000$ sales/month in 2008 to $>8000$ sales/month in 2009. ${ }^{13}{ }^{14}$ A range of factors such as accessibility, 
increased media coverage, anonymity, convenience and lack of need for prescription may make pharmacies and community reproductive health clinics preferred sources of EHC, compared with general practice.

\section{Age-specific contraceptive provision}

Older women (46-55 years) were least likely to be provided with COC compared with younger age groups. This might be expected, given the need for careful assessment of older women before using this method, especially among those with cardiovascular risk factors. ${ }^{15}$ Furthermore, older women are more likely to have completed their families, and therefore maybe more willing to consider longer-acting methods of contraception (including sterilisation) compared with younger women.

Women aged 20-35 years were more likely to be prescribed a LARC by the general practices compared with those aged 16-19 years. Studies have shown that young people's knowledge of, and interest in, LARCs is generally low. ${ }^{16}$ Younger people may have concerns that implants could be visible or leave scars ${ }^{16}$ and that IUDs may affect long-term fertility. ${ }^{17}$ Our study found that adolescent women (aged 16-19 years) were the most likely recipients of EHC from general practice. This is consistent with other studies, which reported that women under the age of 25 years were the most likely users of EHC. ${ }^{18}$

An age difference in the provision of LARCs and EHCs was apparent. It is important that all women wishing to access contraceptives are aware of the various methods available, including LARCs. LARCs have the benefit of overcoming the barrier of lack of compliance, therefore decreasing the need for emergency contraception.

Finally, with regard to smoking status and the provision of contraception, our study found that smokers and ex-smokers were more likely to be provided with a LARC or EHC compared with non-smokers, supporting evidence from an earlier study. ${ }^{19}$ American studies have reported that smoking is associated with higher alcohol consumption and risk-taking behaviour, ${ }^{20}$ which might explain the higher use of EHC among smokers.

\section{Strengths and limitations of the study}

A large number of general practices contributed to the study $(n=191)$ from a total of 1044 practices across Scotland (in 2009). Two of the Scottish Health Boards were not represented in the study sample. Previous analyses have shown that practices that supplied data to the PCCIUR database were broadly similar to most practices in Scotland. ${ }^{21}$

Our study only included data from prescriptions from general practices. Data from other contraceptive providers, including community pharmacies and community reproductive health clinics, were not available. Similarly, information about non-prescribed barrier methods or other contraceptive methods used by women or their male partners was not available. Although female sterilisation may have been recorded by some practices (from hospital discharge letters), it was not possible to record this robustly or to link women with their partners to identify couples who used vasectomy as their method of contraception.

We studied the 'incidence' in provision of contraception. We were not confident that dates of contraceptive discontinuation were recorded for all women, especially if another service provider such as a community clinic removed a device. We were therefore unable to calculate the prevalence of LARC use. Some women may have been provided with the COC or IUS for idiopathic menorrhagia rather than for contraception. It was not possible to determine the extent to which this occurred, although the frequency of such usage is likely to be low. Finally, caution must be exercised when interpreting cross-sectional data such as ours since they cannot demonstrate a direct link between any policy or clinical developments and changes in contraception provision.

\section{CONCLUSIONS}

This study provides information on the contraceptive services that are provided by a large sample of general practices in Scotland. There was an increase in the provision of hormonal contraceptives and LARCs during the study period, and a decline in EHC provision. It is important that a full range of contraceptive options remains easily available to women.

Acknowledgements The authors want to thank Cristina de Cario and Alisdair Coutts for the preparation and processing of the PCCIUR database. They are grateful to Dr Gillian Flett,

Consultant and Head of Service/Sexual Health Clinical Lead, NHS Grampian, for her advice.

Funding This study was funded by a University of Aberdeen Student Research Scholarship.

Competing interests The Centre of Academic Primary Care has received payments from Schering Plough and Wyeth

Pharmaceuticals for lectures and advisory board work provided by Philip Hannaford. None of the other authors have any conflicts of interest to declare. The data contained herein were provided by the Primary Care Clinical Informatics Unit (PCCIU) at the University of Aberdeen. The views in this publication are not necessarily the views of the University of Aberdeen, its agents, or employees.

Provenance and peer review Not commissioned; externally peer reviewed.

Data sharing statement The datasets used for the study are held in the Centre of Academic Primary Care (CAPC). These data could be made available to researchers outside the existing research team for requests which fulfil PCCIUR requirements regarding data use and protection.

\section{REFERENCES}

1 Family Planning Association. Fact Sheet: Abortion. 2010. http://www.fpa.org.uk/media/uploads/professionals/ factsheets-non-printing/abortion-factsheet-august-2010.pdf [accessed 12 January 2013].

2 Office for National Statistics. Contraception and Sexual Health 2008/09. 2008. http://www.statistics.gov.uk/downloads/ theme_health/contra2008-9.pdf [accessed 3 August 2010]. 
3 Department of Health. The National Strategy for Sexual Health and HIV. 2000. http://www.medfash.org.uk/publications/ documents/nat_shs-2001.pdf [accessed 8 September 2010].

4 Scottish Executive. Respect and Responsibility: Strategy and Action Plan for Improving Sexual Health. 2005. http://www. scotland.gov.uk/Resource/Doc/35596/0012575.pdf [accessed 9 November 2012].

5 National Health Service (Scotland). Health Board Additional Pharmaceutical Services (Public Health Service) (Scotland) Directions 2008. 2008. http://www.communitypharmacy.scot.nhs. uk/documents/epharmacy/phs/Community_Pharmacy_Contract_ PHS_Directions_2008.pdf [accessed 13 September 2010].

6 National Pharmacy Association (NPA). Emergency contraception free in Wales. 2011. http://www.npa.co.uk/ resources/press-releases/government-and-public-affairs/ emergency-contraception-free-in-wales-national-pharmacyassociation-comments-/ [accessed 19 May 2011].

7 Harrison-Woolrych M, Howe J, Smith C. Improving access to emergency contraception. BMJ 2001;322: 186-187.

8 National Institute for Health and Clinical Excellence. Long-acting Reversible Contraception (Clinical Guideline No. 30). 2005. http://www.nice.org.uk/nicemedia/pdf/ CG030fullguideline.pdf [accessed 3 August 2010].

9 McLoone P. Carstairs scores for Scottish postcode sectors from the 2001 Census. MRC Social \& Public Health Sciences Unit. Report March 2004. Glasgow, UK; 2004;1-57.

10 British National Formulary. Combined hormonal contraceptives, intra-uterine devices, oral progestogen-only contraceptives. London, UK: BMJ Group \& Pharmaceutical Press; 2010;481-501.

11 Wellings K, Zhihong Z, Krentel A, et al. Attitudes towards long-acting reversible methods of contraception in general practice in the UK. Contraception 2007;76:208-214.
12 Information Services Division (ISD) Scotland. Final population based KCI report - LARC: 2009/20010. 2010. http://www. isdscotland.org/Health-Topics/Sexual-Health/ Key-Clinical-Indicators/Final\%20KCI\%20LARC\%2020010\% 2027092010\%20(2).pdf [accessed 22 November 2012].

13 Bayer Schering Pharma from I.M.S. Health, Regional sales analysis (RSA) data, December 2011 (Scotland only).

14 Glasier A, Manners RJ, Loudon JC, et al. Community pharmacists providing emergency contraception give little advice about future contraceptive use: a mystery shopper study. Contraception 2010;82:538-542.

15 World Health Organization. Medical Eligibility Criteria for Contraceptive Use (3rd edn). 2004. http://whqlibdoc.who.int/ publications/2004/9241562668.pdf [accessed 20 December 2010].

16 Say R, Mansour D. Contraceptive choice for young people. J Fam Plann Reprod Health Care 2009;35:81-85.

17 Glasier A, Scorer J, Bigrigg A. Attitudes of women in Scotland to contraception: a qualitative study to explore the acceptability of long-acting methods. J Fam Plann Reprod Health Care 2008;34:213-217.

18 Schein AB. Pregnancy prevention using emergency contraception: efficacy, attitudes, and limitations to use. J Pediatr Adolesc Gynecol 1999;12:3-9.

19 Rowlands S, Devalia H, Lawrenson R, et al. Repeated use of hormonal emergency contraception by younger women in the UK. Br J Fam Plann 2000;26:138-143.

20 Hiltabiddle SJ. Adolescent condom use, the health belief model, and the prevention of sexually transmitted disease. J Obstet Gynecol Neonatal Nurs 1996;25:61-66.

21 Elder R, Kirkpatrick M, Ramsay R, et al. Measuring quality in primary care medical services using data from SPICE. NHS National Services Scotland 2007.http://www.em-online.com/ download/medical_article/36074_SPICE_Report_July_2007. pdf [accessed 25 February 2012]. 